\title{
Finite element modelling of the pull-apart formation: implication for tectonics of Bengo Co pull-apart basin, southern Tibet
}

\author{
Ganesh Raj Joshi*, Daigoro Hayashi
}

Simulation Tectonics Laboratory, University of the Ryukyus, Okinawa, Japan; *Corresponding Author: ganeshr_joshi@hotmail.com

Received 29 January 2010; revised 12 March 2010; accepted 16 April 2010.

\section{ABSTRACT}

The tectonic deformation and state of stress are significant parameters to understand the active structure, seismic phenomenon and overall ongoing geodynamic condition of any region. In this paper, we have examined the state of stress and crustal deformation during the formation of the Beng Co pull-apart basins produced by an enéchelon strike-slip fault systems using 2D Finite Element Modelling (FEM) under plane stress condition. The numerical modelling technique used for the experiments is based on FEM which enables us to analyze the static behavior of a real and continues structures. We have used three sets of models to explore how the geometry of model (fault overlap and pre-existing weak shear zone) and applied boundary conditions (pure strike-slip, transpressional and transtensional) influence the development of state of stress and deformation during the formation of pull-apart basins. Modelling results presented here are based on five parameters: 1) distribution, orienttation, and magnitude of maximum $\left(\sigma_{\mathrm{H} \max }\right)$ and minimum $\left(\sigma_{\mathrm{H} \max }\right)$ horizontal compressive stress 2) magnitude and orientation of displacement vectors 3 ) distribution and concentration of strain 4) distribution of fault type and 5) distribution and concentration of maximum shear stress $\left(\sigma_{\mathrm{H} \text { max }}\right)$ contours. The modelling results demonstrate that the deformation pattern of the en-échelon strike-slip pull-apart formation is mainly dependent on the applied boundary conditions and amount of overlap between two master strike-slip faults. When the amount of overlap of the two master strike-slip faults increases, the surface deformation gets wider and longer but when the overlap between two master strike-slip faults is zero, block rotation observed significantly, and only narrow and small surface deform- ation obtained. These results imply that overlap between two master strike-slip faults is a significant factor in controlling the shape, size and morphology of the pull-apart basin formation. Results of numerical modelling further show that the pattern of the distribution of maximum shear stress $\left(\tau_{\max }\right)$ contours are prominently depend on the amount of overlap between two master strike-slip faults and applied boundary conditions. In case of more overlap between two masters strike-slip faults, $\tau_{\max }$ mainly concentrated at two corners of the master faults and that reduces and finally reaches zero at the centre of the pull-apart basin, whereas in case of no overlap, $\tau_{\max }$ largely concentrated at two corners and tips of the master strike-slip faults. These results imply that the distribution and concentration of the maximum shear stress is mainly governed by amount of overlap between the master strike-slip faults in the en-échelon pull-apart formation. Numerical results further highlight that the distribution patterns of the displacement vectors are mostly dependent on the amount of overlap and applied boundary conditions in the en-échelon pull-apart formation.

Keywords: State of Stress; Deformation Regime; Pull-Apart Formation; Numerical Modelling; Southern Tibet

\section{INTRODUCTION}

Pull-apart basins are the prominent feature of topographic depression structures formed as result of crustal extension associated with either right-lateral right-stepping or left-lateral left stepping en-échelon strike-slip fault systems $[1,2]$. They usually show a rhombic to spindleshape, and occur at different ranges of size from small sag ponds of few millimeters up to several kilometers 
such as the Dead Sea basins [3,4]. The ratio between the length and width of the pull-apart basins mainly varies between 3 and 4 [5], but recorded pull-apart basins from different part of the world show significance differences in their geometry and structural characteristics [5-7]. Several mechanisms have been proposed for the formation of the pull-apart basins (Figure 1) but the common types of mechanism are 1) local extension between two en-échelon basement strike-slip fault segments 2) a distributed simple strike-slip shear mechanism and 3) the Riedel shear mechanisms. The relative motion of the crust blocks involve in a pull-apart system can either be parallel or oblique and divided into pure strike-slip, transtensional or transpressional (Figure 2(1)). The formation of pull-apart basin geometry exhibits different shapes before, during and after the tectonic deformation as illustrated in Figure 2(2).

\section{Simple formation of pull-apart basins in strike-slip systems}
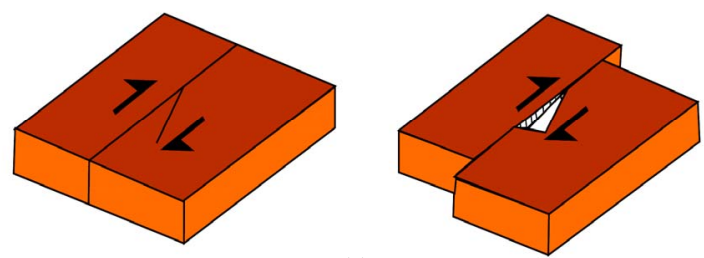

(a)
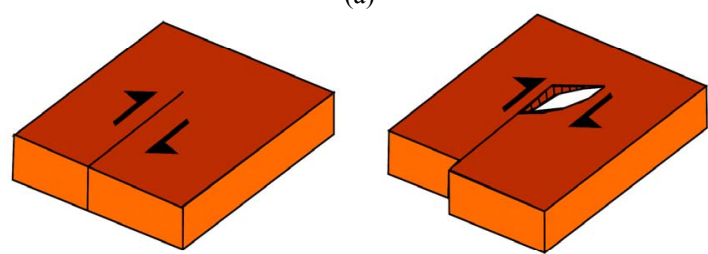

(b)
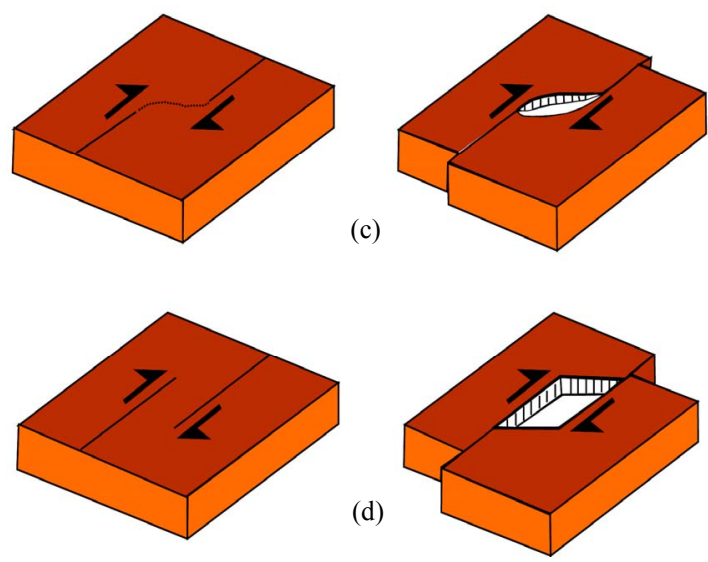

Figure 1. Simple formation of pull-apart basins in strike-slip systems. (a) Formation of a pull-apart basin along the releasing band (b) Formation of a pull-apart basin at the termination of a strike-slip fault (c) Formation of a pull-apart basin at the releasing band and (d) Formation of a pull-apart basin at the releasing overstep along a strike-slip fault.

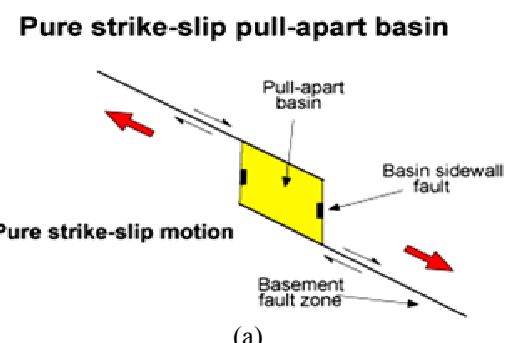

(a)

Transtensional pull-apart basin

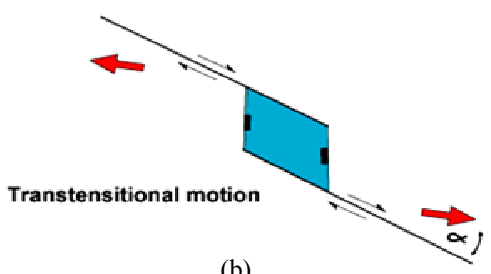

(b)

Transpressional pull-apart basin

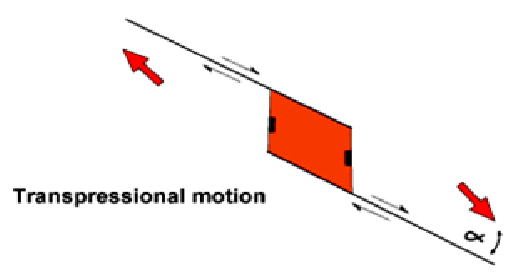

(c)

(1)

Pre-Deformation

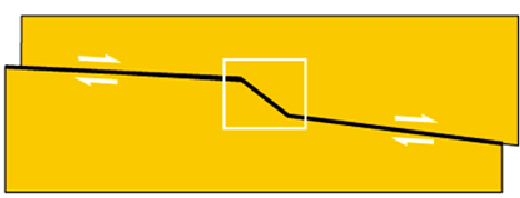

(a)

Post-Deformation

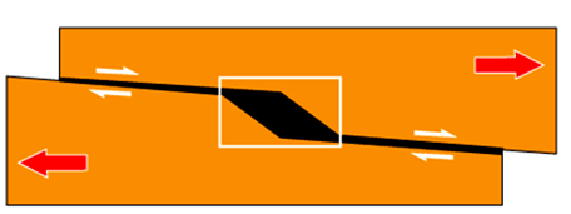

(b)

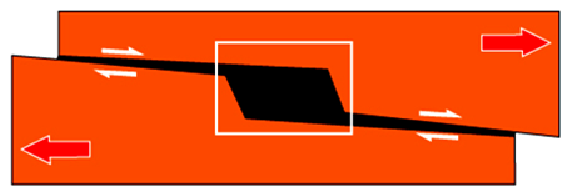

(c)

(2)

Figure 2. (1) General characteristics of strike-slip pull-apart systems developing in (a) pure strike-slip (b) transtensional, and (c) transpressional conditions. (2) Plan view of the formation of pull-apart basin geometry (a) before and (b) during and (c) after tectonic deformation. 
Pull-apart basins are the preferred sites of concentrated fracturing [8], elevated heat flow [9] and intense seismicity [10-12]. Moreover, they have significant economical importance and can confine hydrocarbon [13], significant mineralization [14] geothermal fields [15]. Thus, it is important to study the pull-apart basin and their relative role for hydrocarbon aspect. In recent years, many pull-apart basins have been studied extensively in the several parts of the world [11-17]. Several continental pull-apart basins have been also documented in the Tibetan Plateau [11,12] but there is very few studies have been done to focus the pull-apart basin so far. Present study is the first attempt to model numerically Beng Co pull-apart basin in the southern Tibet.

Numerical modelling is a powerful tool, which provides useful insights that are beyond direct observations e.g. stress state, characteristics structures, sequential evolution of the basin, deformation pattern during evolution of the basin, possible temperature regime and rheology during and after the pull-apart formation. Therefore, numerical models have been extensively applied for studying the pull-apart basins [1,2,7,16,18-20]. Segall and Pollard [16] used the analytical models based on the infinitesimal strain theory. They maximized the displaycement near the middle of the faults with the application of remote external stress. These models provide signifycant clues to the orientations of different faults which can develop inside the overstep area. Gölke et al. [19] analyzed the vertical displacement and topographic variations in the releasing overstep along the master strike-slip faults by using finite element model. Katzman et al. [1] applied the 3D boundary element models of pull-apart basin and compared the modelling results to the Dead Sea Basin. Their results show that the basin deformation mainly depends on the width of the shear zone and on the amount of the overlap between the basinbounding faults. Petrunin and Sobolev [2,20] presented the $3 \mathrm{D}$ thermo-mechanical models of the pull-apart basin developed at an overstepping of an active continental transform faults, and found that the thickness of the brittle layer beneath the basin has significant role in controlling the dimension and deformation pattern of the basin. From their modeling, they further conclude that the deep narrow pull-apart basins are relatively well developed in cold lithosphere, as in the Dead Sea Basin and require very low friction at major faults [2]. Although numerical modelling studies have been applied extensively for simulating deformation in the pull-apart basins, but much less is known overall kinematics or geodynamics within the shallow pull-part structure, as it is filled by unconsolidated sediments, high structurally disrupted or crystallizing materials (veins/plutons).
The purpose of this paper is to understand the relationship between fault geometry; applied boundary conditions (pure strike-slip, transtensional and transpressional), imposed displacements with state of stress and tectonic deformation pattern within a releasing overstep along the two en-échelon strike-slip pull-apart formation applying different sets of models. We have used a series of 2D finite element calculations incorporating elastic rheology under plane stress condition using Mohr-Coulomb failure criterion of faults formation.

\section{GEOLOGY AND TECTONIC SETTING}

The tectonic evolution and uplift of the Tibetan Plateau are a result of tectonic events which occurred due to Indian and Asian plate convergence [21]. The continuing northward movement of the Indian plate for the past $10 \mathrm{Myr}$ has lead to the Tibetan Plateau experiencing widespread extension as indicated by the large scale normal faults and strike-slip zones that made several extensional features such as graben, rift-systems and pull-apart basins in Late Quaternary time [12,21,22]. The tectonic evolution and contemporary states of stress on the Tibetan plateau are mainly governed by E-W extension and N-S compression. The present day average state of stress of the Tibetan Plateau is subject to an extensional $\left(\sigma_{3}\right)$ axis trending $112 \pm 6^{\circ}$ and the minimum horizontal stress $\left(\sigma_{\mathrm{H} \text { min }}\right)$ trajectory trends WNW-ESE. The compressional $\left(\sigma_{1}\right)$ axis trends $022 \pm 6^{\circ}$ and the maximum horizontal stress $\left(\sigma_{\mathrm{H} \text { max }}\right)$ trends N-S to NNE-SSW direction, roughly parallel to the Indian-Eurasian convergence in the central part of the India-Asia collision zone [22].

The Beng Co basin is en-échelon strike-slip pull-apart basin named after the $25 \mathrm{~km}$ long and $7 \mathrm{~km}$ wide Beng Co lake. It developed within the Late Ceneozoic time [12], and is located at $31^{\circ} 10^{\prime} \mathrm{N}$ and $91^{\circ} 10^{\prime} \mathrm{E}$ (Figure 3). It is about $40 \mathrm{~km}$ long with an average strike of north $122^{\circ} \mathrm{E}$ originating from the long side of Beng Co and extending toward the NW and SE strike-slip fault zone. Geological field observations along the Beng Co can identify, two major fault strands and composed of series of en-échelon pull-apart basins. An en-échelon arrangement of the mole tracks in the field implies possible evidence of the right-lateral strike-slip nature of the Beng Co pull-apart [11]. The Beng Co Fault Zones (BCFZ) cut obliquely across folded Jurassic black shale and calcschists, whereas the southern branch of the fault zone runs mostly in the granites and the Jurassic shales. The northern exposure of the BCFZ cuts highly folded, earlyto-middle Cretaceous red sandstone which lie unconformably upon the Jurassic shales [11]. Further northwest, it passes through the area where ophiolites have been thrust southward on the Jurassic shales and truncates 


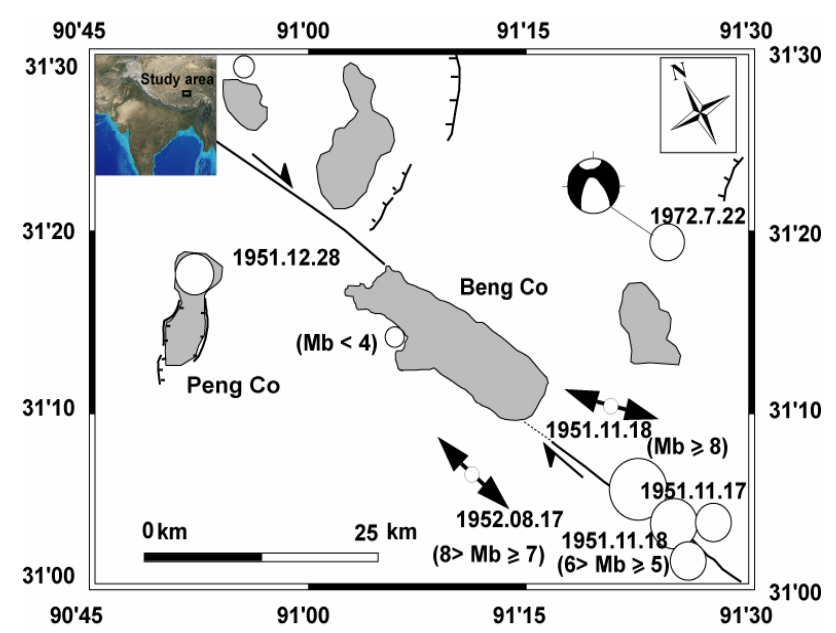

Figure 3. Seismotectonic map of the Beng Co region after (Armijo, 1989). Fault plane solution of July 22, 1972, earthquake is from Molnar and Chen (1983) [33]. Black arrows represent tensional directions deduced from analysis of recent minor faults are from Mercier et al. (1987) [22].

towards the gently folded conglomerates. The southern branch of the BCFZ lies along the southern edge of a NW-SE granite range.

\section{SEISMICITY OF THE REGION}

The Tibetan Plateau is one of the highest and most active region of the world, which evolved as a consequence of the collision between India and Eurasia landmasses about $50 \mathrm{Ma}$ ago [21]. The continuous northward penetration of Indian crust within Eurasia resulted significant amount of stress accumulation, causing intense seismicity and active tectonic nature of the plateau. In the Tibetan region, seismicity is observed mostly from shallow to intermediate depths. Generally, the seismic pattern shows diffuse in nature and does not follow any known particular tectonic trends. The focal mechanisms solutions here are predominantly of normal and strike-slip type, which further attributed to the large scale E-W extension of the region [23].

The field observations provide several evidences of Quaternary displacements, ruptures and large offsets on either side of the Beng Co pull-apart basin. Several prominent, continuous and fresh surface breaks with large numbers of paleoseismic events along the zone imply that the Beng Co pull-apart region is seismo-tectonically active in contemporary time. Evidence includes several major earthquakes including November 17 and 18, 1951 $\left(\mathrm{M}_{\mathrm{W}}=8\right)$; August 17, 1952; December 28, 1951 and July 12,1972 , which show a magnitude $\left(\mathrm{M}_{\mathrm{W}}\right)>6$, and are located near the southern extremity of the Beng Co pull-apart (Figure 3).

\section{MODELLING}

Numerical simulations are essential for creating an understanding of the physics behind the observations of surface displacement and strain. This is particularly important for understanding data related to active tectonics and earthquake phenomenon because earthquake cycles occur on timescales of thousands of years and our observations sample only a small part of that system. The numerical modelling technique used for the experiments is based on a Finite Element Modelling (FEM) which enables us to analyze the static and behavior of real and continuous structures. FEM has successfully proved to be a powerful method for simulating pull-apart basin geometries and deformation mechanisms, $[1,2,7,16,18$, 19]. In this study, we applied a $2 \mathrm{D}$-finite element software package developed by Hayashi [24], which has been used widely by Joshi and Hayashi, [25-27]. Similar to most mesh-based numerical methods, bodies of rocks in this program are represented by triangular elements and each element is assigned appropriate material properties, such as density, Young's modulus, cohesion and angle of internal friction. The mesh deforms and moves with respect to material and able to compute appropriate deformation in the program. The details of mathematical formulations about the software package have already described by Hayashi [24].

\subsection{Model Setup}

The dimension of the models are $42 \mathrm{~km}$ in length and 7.5 $\mathrm{km}$ in width which mimic the natural dimension of the Beng Co pull apart basin adopted after Armijo et al. [11] (Figure 3). We simplified the model and divide the model area into triangular mesh and several domains. The initial mesh of the model consists of 546 nodal points, 984 triangular elements and two master right-lateral strike-slip faults. In the model, we assumed that the upper crust is a brittle layer and is treated as elastic material. In order to simulate the brittle deformation mechanism of the model, we adopt elastic rheology under plane stress conditions. In our model, the crust up to 20 $\mathrm{km}$ is considered to behave as an elastic material because of its brittle nature and presence of earthquake and faults. Rocks forming the brittle crust of the earth contain inhomogeneities which may result in differences compared with our homogeneous and uniform model. In spite of these limitations, our models are still able to yield valuable information related to the pull-apart formation.

\subsection{Boundary Condition}

For the modelling purpose, a two dimension Cartesian rectangular simplified model which shows original ge- 
ometry of the Beng Co pull-apart basin has been adopted after Armijo et al. [11] (Figure 4). Far-field plate velocity boundary conditions are enforced at the either side of the Beng Co Fault Zones (BCFZ). The brittle crust is divided into three simple domains, which may exhibit dissimilar rock layer properties. Domain 1 and 2 represent the southern and northern flank of the pre-existing BCFZ, and domain 3 represents surrounding regions. We consider typical two types of models 1) a model with a pre-existing pull-apart basin and 2) a model without pre-existing pull-apart basin. The model without a pre-existing pull-apart basin is further tested into different overlap/separation ratios (Model B and Model C). We imposed three types of reasonable boundary conditions to mimic the possible natural strike-slip environment of the pull-apart formation. These displacement boundary conditions are 1) pure strike-slip 2) transtensional and 3) transpressional conditions (Figure 4). The empirical 100 to $500 \mathrm{~m}$ displacements were imposed from northern-left and southern-right corners in different boundary environments, and only $10 \%$ of imposed displacement is considered for transtensional and transpressional conditions for modelling (Figure 4).

\subsubsection{BC1: Pure Strike-Slip Model}

The pure en-échelon strike-slip boundary conditions were obtained by moving the upper left-hand and lowerright hand corners using displacement in the left $(-\mathrm{X})$ and right $(+\mathrm{X})$ directions while the lower and upper edges are fixed (Figure 4(a)). This boundary condition explores the effect of pure-strike-slip movements on the overall stress field and faulting regime on the pull-apart formation.

\subsubsection{BC2: Transtensional Model}

The transtensional boundary conditions were simulated by moving the upper left-hand and lower-right hand corners using displacement in the left $(-X)$ and right $(+X)$ directions, and adding an outward displacement in left $(-Y)$ and right $(+Y)$ directions to the lower and upper edges of the model respectively (Figure 4(b)). This boundary condition provides the opportunity to understand the distribution and orientation of the stress field and deformation style of the transtensional environment of the pull-apart formation.

\subsubsection{BC3: Transpressional Model}

In order to investigate the state of stress and overall deformation of the strike-slip pull-apart basin we applied transpressional boundary condition. The transpressional boundary condition were obtained by moving the upper lefthand and lower-right hand corners using displacement in the left $(-X)$ and right $(+X)$ directions with adding an inward displacements in left $(-\mathrm{Y})$ and right $(+\mathrm{Y})$ directions to the lower and upper edges, respectively (Figure 4(c)).

\subsection{Mechanical Parameters and Rock Domain Property}

The mechanical properties such as density $(\rho)$, Young's modulus $(E)$, Poisson's ratio $(v)$, angle of internal friction $(\phi)$ and cohesive strength (c) are important rock
Model A

(a) Pure Stnike-Slip condition
Model B

Model C
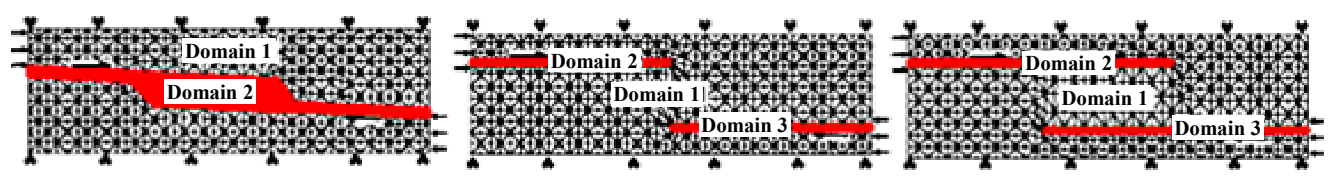

(b) Trantensional condition
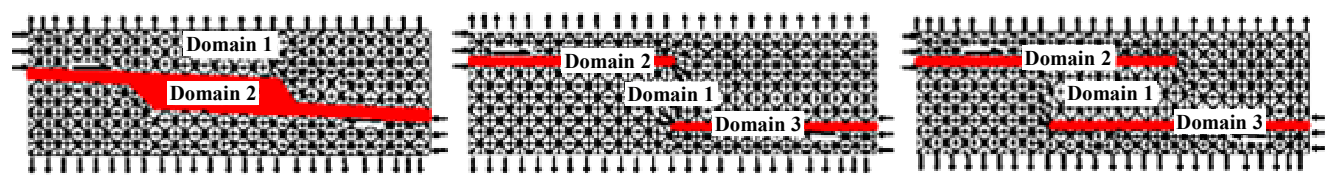

(c) Transpressional condition
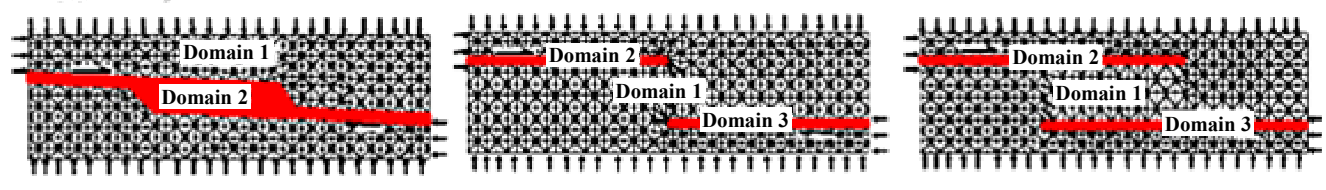

Figure 4. Simplified finite element model partition with geometry and boundary conditions for Models $\mathrm{A}, \mathrm{B}$ and $\mathrm{C}$. The triangular elements show the finite element grid. 
parameters in the FEM analysis (Table 1). The density $(\rho)$ was obtained from the interval velocity of the individual rock domain, using the relation proposed by Barton [28] and compared them with published velocity model [29] from southern Tibet. Seismic $P$-wave $\left(V_{p}\right)$ and S-wave $\left(V_{s}\right)$ velocities are chosen from the published literature of the study area [30]. We have used two independent elastic constants, Young's modulus and Poisson's ratio to solve the following elastic equations in the brittle part of the lithosphere [24,31].

$$
\begin{aligned}
& E=\rho V_{p}^{2} \frac{(1+v)(1-2 v)}{(1-v)} \\
& v=\frac{1}{2}\left[1-\frac{1}{\left(V_{p}-V_{s}\right)^{2}-1}\right]
\end{aligned}
$$

where $E$-Young's modulus, $v$-Poisson's ratio, $\rho$-density of rock, $V_{p^{-}}$seismic $P$-wave velocity and $V_{s^{-}}$seismic $S$-wave velocity.

In performing FEM calculation, the whole model is divided into 3 domains and each domain has been allocated distinct rock layer properties on the basis of predominant rock types (Table 1). In case of Model A, we assume that BCFZ is pre-existing weak shear zones which allowed us to adopt the value of Young's modulus less compared to other rock domain. $\phi$ and $c$ were obtained from the Handbook of Physical Constants [32].

\section{MODELLING RESULTS}

To understand the various factors that control the induced state of stress and deformation pattern of the pull-apart basin formation, we have carried out a number of modelling experiments for two characteristic models 1) with a pre-existing pull-apart basin in model and 2) without a pre-existing pull-apart basin in model.

In case of without pre-existing pull-apart basin, we further calculated by two separate models, i.e., Model B and Model C. The Model B which represents no overlap or zero overlap between the two master faults and the Model $\mathrm{C}$ corresponds to considerable overlap between two master en-échelon basement strike-slip faults. Each of these models was run for the three most common types of boundary conditions of pull-apart formation: 1) $\mathrm{BC} 1$ : pure strike-slip condition, 2) $\mathrm{BC} 2$ : transtensional condition, and 3) BC3: transpressional condition. Here, modelling results are represented based on 1) the maximum $\left(\sigma_{\mathrm{H} \max }\right)$ and minimum $\left(\sigma_{\mathrm{H} \text { min }}\right)$ horizontal principle stress 2) magnitude and orientation of the displacement vectors 3) distribution and magnitude of the strain 4) distribution of fault type and 5) concentration and distribution of the maximum shear stress $\left(\tau_{\max }\right)$ contours. The direction and magnitude of the maximum compressive stress axis and minimum compressive stress axis are represented by $\sigma_{1}$ and $\sigma_{3}$, respectively. In addition, we have calculated tectonic deformation and faulting regime on the Beng Co pull-apart basin based on the relation and position of the $\sigma_{1}, \sigma_{2}$ and $\sigma_{3}$ applying Mohr-Coulomb failure criterion.

\subsection{Model A: Pre-Existing Pull-Apart Basin}

Figures 5, 6 and 7 illustrate the orientation of the maximum $\left(\sigma_{\mathrm{H} \max }\right)$ and minimum $\left(\sigma_{\mathrm{H} \min }\right)$, horizontal principle stress trajectories, strain distribution, displacement vectors, contour lines of maximum shear stress $\left(\tau_{\max }\right)$ and development of a faulting regime for Model $\mathrm{A}$ in the pure strike-slip boundary condition. The calculated $\sigma_{\mathrm{H}}$ max trajectories show almost N-S directional orientation with uniform distribution in the model with minor variation in the upper left and lower right corners, which corresponds to the direction of maximum shortening of the Tibetan Plateau (Figures 5(a), 6(a) and 7(a)). Similarly, $\sigma_{\mathrm{H} \text { min }}$ trajectories show more or less E-W orientation, which is also consistent with the direction of maximum extension in the Tibetan Plateau (Figures 5(b), 6(b) and 7(b)). However, some discrepancy was observed in the corners of the models which might be due to boundary effect. The orientations of the displacement vectors show prominent difference among three boundary conditions. The major discrepancy was obtained at the upper-right corner and lower-left corners of the pull-apart basin (Figures 5(c), 6(c), 7(c)). Figures 5(d), 6(d) and 7(d) illustrate the predicted strain partitioning for Model A, where high extensional strain is mainly concentrated along pre-existing weak shear zone. This is due to weak rheology, and consistent with the applied model geometry. The predicted faulting pattern shows almost similar predominantly strike-slip type of faults for all boundary conditions (Figures 5(e), 6(e) and 7(e)). Figures 5(f), 6(f) and 7(f) show concentration and distribution patterns of modeled $\tau_{\max }$ contours for all three boundary conditions, where $\tau_{\max }$ is largely confined at the central part of the pull-apart basin.

\subsection{Without Pre-Existing Pull-Apart Basin}

In this case, two models (Model B and Model C) were used to calculate state of stress and deformation regime

Table 1. Rock mechanical properties used for different domains in the finite element models.

\begin{tabular}{ccccc}
\hline Rock Domain & $\rho(\mathrm{kg} / \mathrm{m} 3)$ & $E(\mathrm{GPa})$ & $c(\mathrm{MPa})$ & $\phi($ deg. $)$ \\
\hline Domain 1 & 2900 & 60.0 & 24.0 & 50.0 \\
Domain 2 & 2000 & 01.0 & 10.0 & 31.0 \\
Domain 3 & 2000 & 01.0 & 10.0 & 31.0 \\
\hline
\end{tabular}



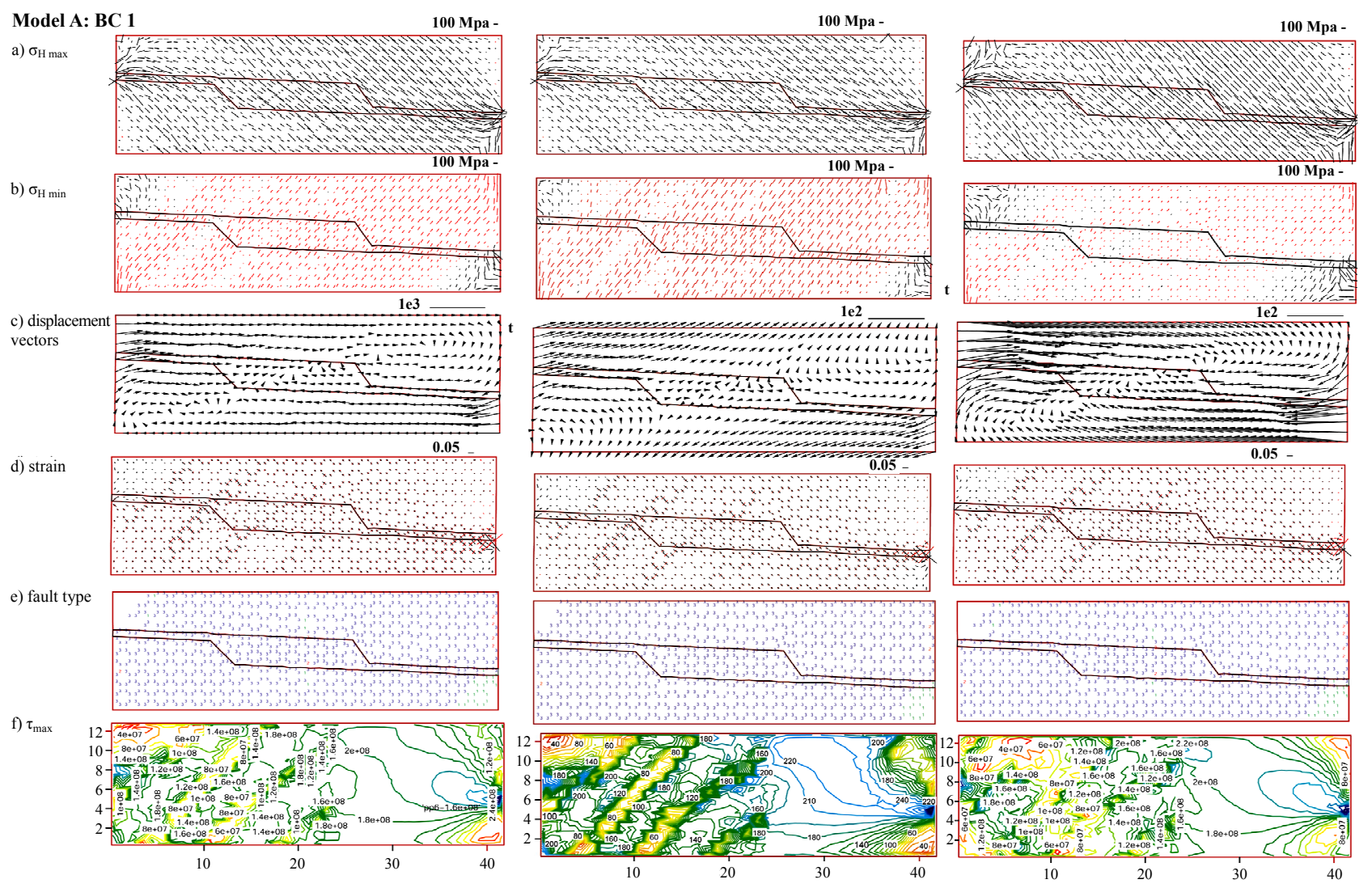

Figure 5. Results of Model A for all three pure strike-slip, transtensional and transpressional boundary conditions. (a) Maximum compressional stress $\left(\sigma_{1}\right)$ trajectories (b) Maximum extensional stress $\left(\sigma_{3}\right)$ trajectories (c) strain distribution (d) displacement vectors (e) faulting regime and (f) distribution of maximum shear stress $\left(\tau_{\max }\right)$ contours under $100 \mathrm{~m}$ boundary displacement condition at 10 $\mathrm{km}$ depth.

of the Beng Co pull-apart basin for understanding the effect of different overlap on the stress distribution. Figures 6 and 7 illustrate the calculated maximum $\left(\sigma_{\mathrm{H}}\right.$ $\max )$ and minimum $\left(\sigma_{\mathrm{H} \min }\right)$ horizontal principle stress trajectories, strain distribution, displacement vectors, contour lines of maximum shear stress $\left(\tau_{\max }\right)$ and development of faulting regime of the Model B and Model C. In both models, orientations of the $\sigma_{\mathrm{H} \text { min }}$ trajectories show more or less E-W directed orientation for all boundary conditions, which is consistent with E-W extension environment of the Tibetan Plateau. A comparison of the Model B and Model C shows that although the general stress $\left(\sigma_{\mathrm{H} \min }\right)$ patterns remain similar, there are significance differences in the distribution and concentration of $\tau_{\max }$ (Figures 6(f) and 7(f)). Similarly, according to applied boundary conditions, the orientation and magnitude of displacement vectors show significant variations between Model B and Model C (Figures 6(c) and $7(\mathbf{c}))$. There are no considerable differences observed in the predicted strain partitioning among both models, where strain is mainly concentrated along the fault zone which is due to weak rheology. The predicted faulting pattern of the model exhibits almost similar predominantly strike-slip types of faults that have developed for all boundary conditions. If we compare pre-existing pull- apart model (Model A) there is significant difference in distribution and concentration of $\tau_{\max }$ contours.

\subsubsection{Model B: Without Overlap on the Pull-Apart basin}

Model B illustrates the results of numerical simulation in the case of no pre-existing pull-apart basin and zero overlap of the two master strike slip faults in the model. Figure 6 illustrates the orientation of $\sigma_{\mathrm{H} \text { max }}$ and $\sigma_{\mathrm{H} \text { min }}$ trajectories, displacement vectors, strain concentration, distribution of $\tau_{\max }$ contours and faulting regimes for Model B. In this model orientation of $\sigma_{\mathrm{H} \text { max }}$ trajectories, strain concentration and faulting regimes which show similar results for all boundary conditions at the same displacement, compared to Models A and C. However, the magnitude of the $\sigma_{\mathrm{H} \text { min }}$ trajectories shows little differences between $\mathrm{BC} 1$ and $\mathrm{BC} 3$, and the predicted results of displacement vectors and distribution of $\tau_{\max }$ show considerable differences between three applied boundary 
conditions. Figure 6(c) illustrates the principal variations of predicted displacement vectors among three boundary conditions (i.e., BC1, BC2 and BC3) for Model B. Similarly, Figure 6(f) shows how differently $\tau_{\max }$ is distributed for the different boundary conditions in Model B.

\subsubsection{Model C: With Fault Overlap on the Pull-Apart Basin}

Model $\mathrm{C}$ predicted the results of numerical simulation taking into account pre-existing overlap of the two master strike slip faults in the Beng Co pull-apart basin. Figure 7 illustrates the orientation of $\sigma_{\mathrm{H} \max }$ and $\sigma_{\mathrm{H} \text { min }}$ trajectories, displacement vectors, strain concentration, distribution and accumulation of $\tau_{\max }$ and overall faulting regimes for Model C. Results show that there are no considerable variations of the distribution and orientation of the predicted $\sigma_{\mathrm{H} \text { max }}$ and $\sigma_{\mathrm{H} \text { min }}$ trajectories, strain partitioning and faulting regime. Nevertheless, high discrepancies do exist in case of displacement vectors (Figure $7(\mathbf{c})$ ) and distribution and concentration of $\tau_{\max }$ contours (Figure 7(f)). If we compare distribution and concentration of $\tau_{\max }$ to other models the Model $\mathrm{C}$ does not predict $\tau_{\max }$ in the centre of the pull-apart basin which is possibly due to the fault overlap geometry. Moreover, major difference appear in predicted the maximum extensional stress $\left(\sigma_{3}\right)$ trajectories within the Model $\mathrm{C}$ (Figure 7(b)), which might be the cause of the applied boundary condition.

\section{DISCUSSIONS}

\subsection{Effect of Pre-Existing Weak Shear Zone of Pull-Apart Basin}

We first explore the effect of a pre-existing weak shear zone of pull-apart basin on the stress field and deformation pattern during formation of the pull-apart basin. Figure 5 illustrates the modelling results of a pre-existing weak shear zone of Beng Co strike-slip pull-apart basin. In order to quantify the relative importance of a pre-existing strike-slip weak shear zone on the pullapart basin the modelling results are compared between Model A and Model B. A close examination of results of

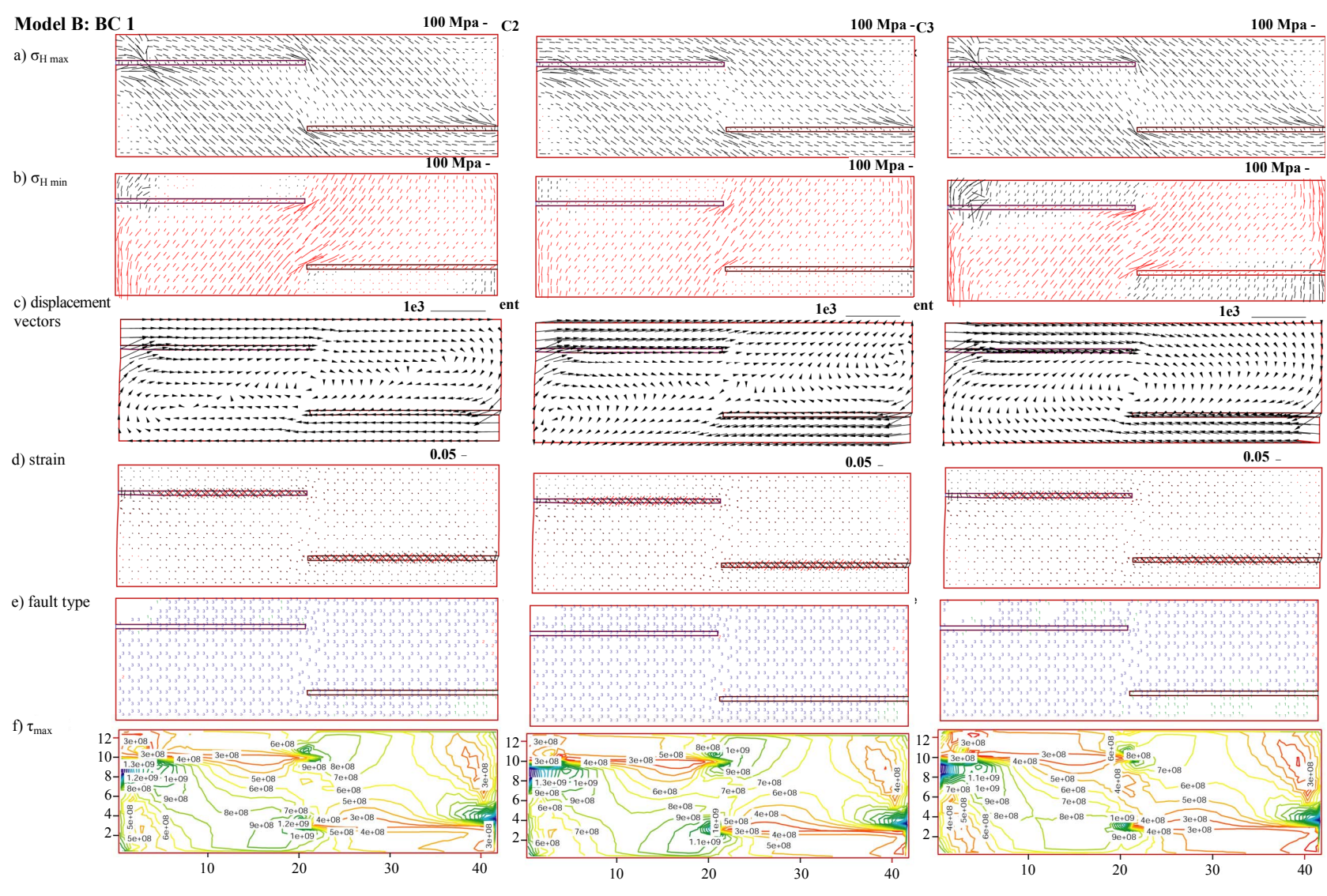

Figure 6. Results of Model B for all three pure strike-slip, transtensional and transpressional boundary conditions.(a) Maximum compressional stress $\left(\sigma_{1}\right)$ trajectories (b) Maximum extensional stress $\left(\sigma_{3}\right)$ trajectories (c) strain distribution (d) displacement vectors (e) faulting regime and (f) distribution of maximum shear stress $\left(\tau_{\max }\right)$ contours under $100 \mathrm{~m}$ boundary displacement condition at 10 km depth. 


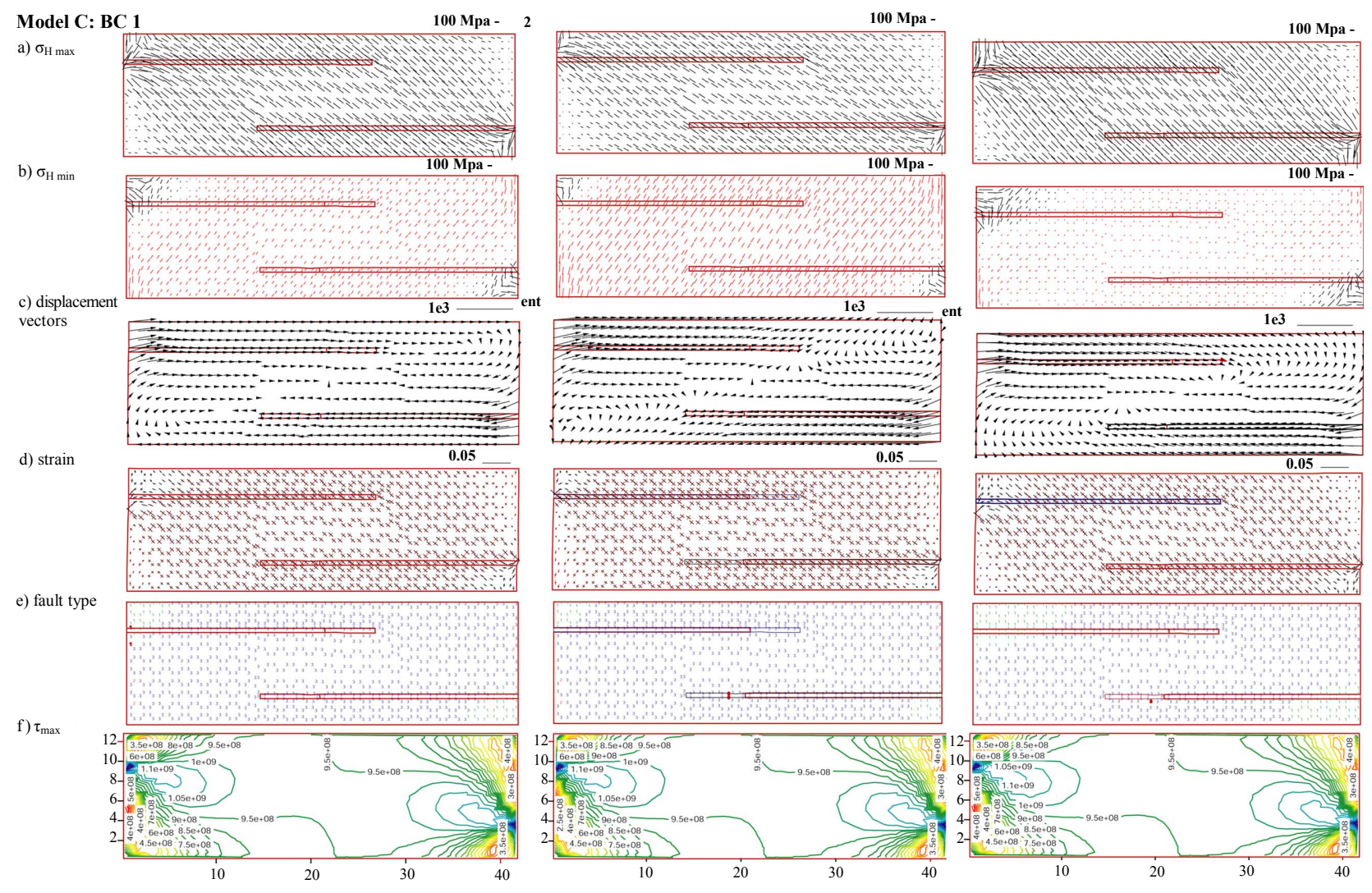

Figure 7. Results of Model C for all three pure strike-slip, transtensional and transpressional boundary conditions. (a) Maximum compressional stress $\left(\sigma_{1}\right)$ trajectories (b) Maximum extensional stress $\left(\sigma_{3}\right)$ trajectories (c) strain distribution (d) displacement vectors (e) faulting regime and (f) distribution of maximum shear stress $\left(\tau_{\max }\right)$ contours under $100 \mathrm{~m}$ boundary displacement condition at 10 km depth.

these two models demonstrate that major disparities exist in the horizontal displacement vectors and distribution and concentration of $\tau_{\max }$ contour lines, whereas minor differences also exist with regards to the orientation and magnitude of the horizontal principal stresses and deformation pattern, which indicate that the effect of the pre-existing weak shear zone of the pull-apart basin are important control on distribution and concentration of $\tau_{\max }$, and principal stresses direction.

\subsection{Effect of Change in Boundary Conditions in Pull-Apart Formation}

Boundary conditions are important factors for controling the stress state and deformation patterns of the model. Therefore, we explore the effect of a change in boundary conditions on the stress field and deformation style in the formation of the pull-apart basin. In order to investigate the effect of boundary conditions in stress field and deformation patterns, we have tested three types 1) pure strike-slip 2) transtensional and 3) transpressional of boundary conditions. Figures 5, 6 and 7 show predicted modelling results of the $\sigma_{\mathrm{H} \max }, \sigma_{\mathrm{H} \text { min }}, \tau_{\max }$ displacement vector, strain partitioned and faulting regime for all three models. Modelling results clearly demonstrated that the distribution and concentration of $\tau_{\max }$, displacement vectors and dimension of the pull-apart basin in each boundary condition varies significantly, while orientations of the $\sigma_{\mathrm{H} \text { max }}$ and $\sigma_{\mathrm{H} \text { min }}$ are moderately influenced and faulting regime is not effected by changing applied boundary conditions.

\subsection{Effect of Change in Fault Overlap in Pull-Apart Development}

To investigate the effect of change in the two en-échelon faults overlap geometry we have considered two separate models having 1) zero fault overlap (Model B), and 2) with fault overlap (Model C). Figure 7 shows the predicted result of fault overlap Model C. If we compare the predicted results of this model with other two models (Model A and Model C) (Figures 6 and 7) we observed that the major differences among models are in the orientation of displacement vectors, and distribution and concentration of the $\tau_{\max }$ contours. The large rotation of 
the horizontal displacement vector appears in the central part of the pull-apart basin with zero overlap model (Model B), while no significant rotation of displacement vector observed in the overlap model (Model C). The Model $\mathrm{C}$ produced a tentative rectangular and wide pullapart basin, while Model B produced a narrow and small pull-apart basin (Figures 6 and 7). Moreover, simulated results from our models clearly show that if the faults overlap increases, the size of the pull-apart basin also increases and if the fault overlap decreases the size of the pull apart basin decreases, considerably. These results of numerical modelling imply that fault overlap geometry has an extensive control on the change in shape, size and morphology of the pull-apart formation, which is consistent with previous studies such as Gölke, et al., [19]. Moreover, fault overlap geometry has significant effect on distribution and orientation of $\sigma_{\mathrm{H} \text { min }}$ and concentration of the $\tau_{\max }$ contours but there is no effect on the development of fault type (Figures 6 and 7).

\subsection{Effect of Change in Displacement in Pull-Apart Formation}

The applied displacement is another significant factor that strongly influences on the magnitude and orientation of the stress field and deformation pattern. We have investigated the effect of applied displacement on the deformation and stress regime during the pull-apart development. We have used 100 to $500 \mathrm{~m}$ displacement conditions from the either sides of the model. Our modelling results clearly show that displacement has a major effect on the magnitude and orientation of the maximum $\left(\sigma_{\mathrm{H} \max }\right)$ and minimum $\left(\sigma_{\mathrm{H} \text { min }}\right)$ horizontal stresses and displacement vectors, but minor effect on the style of faulting. This result indicates that the change in displacement significantly influences the magnitude of the stress trajectory but only has a limited effect on the orientation of the pull-apart formation. We have further explored the influence of change in displacement on maximum shear stress $\left(\tau_{\max }\right)$ concentration. The model results demonstrate that if we increase the applied displacement the magnitude and concentration of the $\tau_{\max }$ contour increases considerably and shear strain will become concentrated in the two ends of the master fault zones.

\section{CONCLUSIONS}

A two-dimension finite element numerical model was used to simulate the strike-slip pull-apart basin formation. We examine the state of stress and deformation associated with the right-lateral, en-échelon Beng Co pullapart basin in the southern part of Tibetan Plateau. In this paper, we have considered three models each incorporating three different boundary conditions (pure strike- slip, transtensional and transpressional) with different amount of fault overlap of the master strike-slip fault systems. Our modelling results demonstrate that the deformation pattern of the en-échelon strike-slip pull-apart formation is mainly dependent on the geometry of the pullapart basin, applied boundary conditions and the amount of overlap between two master strike-slip fault systems. When the amount of overlap of the shear zone increases, the surface deformation gets wider and longer between two master faults, but if zero overlap exists between the two strike-slip fault systems, the narrow pull apart formed and block rotation is observed within the pull-apart basin. Based on present modelling we conclude that overlap between two en-échelon strike-slip faults is a significant factor in controlling the shape, size and morphology of the pull-apart formation.

The pattern of the rotation of displacement vectors and maximum shear stress $\left(\tau_{\max }\right)$ distribution contours are also highly dependent on the applied boundary conditions and amount of overlap. In the case of a larger overlap, $\tau_{\max }$ is mainly concentrated at two corners of the master strike-slip faults and reduces toward the centre of the pull-apart basin, whereas for zero overlap conditions, $\tau_{\max }$ is largely concentrated at the two corners and tips of the master strike-slip faults. These results imply that the concentration and distribution of the maximum shear stress $\left(\tau_{\max }\right)$ is principally governed by amount of overlap between the master strike-slip faults in the en-échelon pull-apart formation.

Finally, on the basis of our modelling results we can conclude that the adopted geometry, applied boundary conditions and amount of overlap of the shear zone have a remarkable role in controlling the overall dimension, stress distribution and deformation pattern during the pull-apart formation.

\section{ACKNOWLEDGEMENTS}

G. R. Joshi gratefully acknowledges the Ministry of Education, Sports and Culture (Monbukagakusho) Japan for the financial support to accomplish this research. The authors wish to thank simulation tectonics laboratory members for their help and support during the research.

\section{REFERENCES}

[1] Katzman, R., Brink, U.S. and Lin, J. (1995) Three dimension of modelling of pull-apart basins: Implications for the tectonics of the Death Sea Basins. Journal Geophysical Research, 100(B4), 6295-6312.

[2] Petrunin, A. and Sobolev, S.V. (2006) What controls the thickness and lithospheric deformation at a pull-apart basin? Geology, 34(5), 389-392.

[3] Burchfiel, B.C. and Stewary, J.H. (1966) Pull-apart origin of the central segment of the Death valley. Geological Society of America, 77(4), 439-442. 
[4] Sylvester, A.G. (1988) Strike-slip faults. Bulletin of Geological Society of America, 100(11), 1666-1703.

[5] Ayden, A.A. and Nur, A. (1982) Evolation of pull-apart basins and their scale independence. Tectonics, 1(1), 91105.

[6] Gamond, J.F. (1983) Displacement feature associated with fault zone: A comparison between observed examples and experimental models. Journal of Structural Geology, 5(1), 33-45.

[7] Bahat, D. (1983) New aspects of rhomb structures. Journal of Structural Geology, 5(6), 591-601.

[8] Connolly, P. and Cosgrove, J. (1999) Prediction of fracture-induced permeability and fluid flow in the crust using experimental stress data. AAPG Bulletin, 83(5), 757777.

[9] Hu, S., O’Sullivian, B.P., Raza, A. and Cona, B.P. (2001) Thermal History and tectonic subsidence of the Bohai Basin, northern China: A Cenozoic rifting and pull-apart basins. Physics of the Earth and Planetary Interiors, 126(3-4), 121-135.

[10] Armijo, R., Meyer, B., Navarro, A., King, G. and Barkar, A. (2002) Asymmetric slip partitioning in the Sea of Marmara pull-apart: A clue to propagation processes of the North Anatolian Fault. Terra Nova, 14(2), 80-86.

[11] Armijo, R., Tapponnier, P. and Tonglin, H. (1989) Late Cenozoic right-lateral strike-slip faulting in southern Tibet. Journal of Geophysical Research, 94(B3), 27872938.

[12] Armijo, R., Tapponnier, P., Mercier, L. and Tonglin, H. (1986) Quaternary extension in southern Tibet: Field observations and tectonic implications. Journal of Geophysical Research, 91(B14), 13803-13872.

[13] Harding, T.P. (1990) Identification of wrench faults using sub-surface structural data: Criteria and pitfalls. $A A P G$ Bulletin, 74(10), 1590-1609.

[14] Recherds, P.D., Boyce, A.J. and Pringle M.S. (2001) Geological evolution of the Escondida area, northern Chile: a model for spatial and temporal localization of porphyry $\mathrm{Cu}$ mineralization. Economic Geology, 96(2), 271-305.

[15] Monastero, F.C., Katzenstein, A.M., Miller, J.S., Unruh, J. R., Adams, M.C. and Richerds-Dinger, K. (2005) The Coso geothermal field: A nascent metamorphic core complex. Bulletin of Geological Society of America, 117(11-12), 1534- 1553.

[16] Segall, P. and Pollard, D.O. (1980) Mechanics of discontinuous faults. Journal of Geophysical Research, 85(B8), 4337-4350.

[17] Basile, C. and Brun, J.P. (1999) Transtensional faulting pattern from pull-apart basin to continental margins: An experimental investigation. Journal of Structural Geology, 21(1), 23-37.

[18] Du, Y. and Aydin, A. (1993) The maximum distortion energy density criterion for shear fracture propagation with applications to the growth paths of en-échelon faults. Geophysical research Letters, 20(11), 1091-1094.
[19] Gölke, M., Cloetingh, S. and Fuch, K. (1994) Finite element modelling of pull-apart formation. Tectanophysics, 240(1-4), 45-57.

[20] Petrunin, A. and Sobolev, S.V. (2008) Three-dimensional numerical models of the evolution of pull-apart basins. Physics of Earth and Planatery Interiors. 171(1-4), 387399.

[21] Molnar, P. and Tapponier, P. (1975) Cenozoic tectonics of Asia: Effects of a continental collision. Science, 189(4201), 419-426.

[22] Mercier, J.L., Armijo, R., Tapponinier, P., Carey-Gailhardis, E. and Han, T.L. (1987) Change from late tertiary compression to late quaternary extension, in southern Tibet, during the India-Asia collision. Tectonics, 6(3), 275-304.

[23] Torre, T.L. de la, Monsalve, G., Sheehan, A.F., Sapkota, S. and Wu, F. (2007) Earthquake processes of the Himalayan collision zone in eastern Nepal and the southern Tibetan Plateau. Geophysical Journal International, 171(2), 718-738.

[24] Hayashi, D. (2008) Theoretical basis of FE simulation software package. Bulletin of the Faculty of Science, University of the Ryukyus, 85, 81-95.

[25] Joshi, G.R. and Hayashi, D. (2008a) Neotectonic deformation and shortening along the Himalayan front in the Garhwal region by finite element modelling. Bullettino di Geofisica Teorica ed Applicacate, 49, 228-233.

[26] Joshi, G.R. and Hayashi, D. (2008b) Numerical modelling of neotectonic movements and state of stresses in the central seismic gap region, Garhwal Himalaya. Journal of Mountain Science, 5(4), 279-298.

[27] Joshi, G.R. and Hayashi, D. (2010) Development extensional stresses in the compressional setting of the Himalayan thrust wedge: Inference from numerical modelling. Natural Science (in press).

[28] Barton, P.J. (1986) The relationship between the seismic velocity and density in the continental crust - a useful constraint? Geophysics Journal of the Royal Astronomical Society, 87(1), 195-208.

[29] Zhao, W., Nelson, K.D. and Project INDEPTH Team (1993) Deep seismic reflections evidence for continental underthrusting beneath south Tibet. Nature, 366(6455), 557559.

[30] Cogan, M.J., Nelson, K.D., Kidd, W.S.F., Wu, C. and Project INDEPTH Team (1998). Shallow structure of the Yadong-Gulu rift, southern Tibet, from refraction analysis of Project INDEPTH common midpoint data. Tectonics, 17(1), 46-61.

[31] Timosenko, S.P. and Goodier, J.N. (1970) Theory of elasticity. 3rd Edition, McGraw-Hill Book Company, London.

[32] Clark, Jr., S.P. (Ed.) (1966) Handbook of Physical Constants. New York, Geological Society America, Memoir.

[33] Molnar, P. and Chen, W.P. (1983) Focal depths and fault plane solutions of earthquakes under the Tibetan Plateau. Journal of Geophysical Research, 88(B2), 1180-1196. 


\section{Appendix}

Appendix A is quoted from "Theoretical basis of FE simulation software package" page 84 to 89 written by Hayashi (2008).

\section{2D Elastic Problem}

The principle of virtual work is described that the external works done by virtual displacement equals the internal work done by virtual strain. Let us consider a certain element within a domain concerned as shown in Figure A1. When small displacement $\overline{\mathbf{u}}_{i}$, which is called virtual displacement, is applied to deform the element without disturb the balance of system, the external work is written as

$$
W=\left(\overline{\mathbf{u}}^{e}\right)^{T} \mathbf{f}^{e} \quad \text { where } \overline{\mathbf{u}}^{e}=\left(\begin{array}{c}
\overline{\mathbf{u}}_{1} \\
\overline{\mathbf{u}}_{2} \\
\overline{\mathbf{u}}_{3}
\end{array}\right) \text { and } \mathbf{f}_{e}=\left(\begin{array}{l}
\mathbf{f}_{1} \\
\mathbf{f}_{2} \\
\mathbf{f}_{3}
\end{array}\right)
$$

While taking $\overline{\mathbf{e}}$ as virtual strain derived from virtual displacement and $\mathbf{s}$ as stress, the strain energy of the element are shown as

$$
U=\int_{S}(\overline{\mathbf{e}})^{T} \mathbf{s} d S
$$

According to the principle of virtual work, both must be equated. $\boldsymbol{W}=\boldsymbol{U}$

$$
\begin{aligned}
\left(\overline{\mathbf{e}}^{e}\right)^{T} \mathbf{f}^{e}=\int_{S}(\overline{\mathbf{e}})^{T} \mathbf{s} d S \\
u=a_{0}+a_{i} x_{i} \\
=a_{0}+a_{1} x_{1}+a_{2} x_{2} \\
=\left(\begin{array}{lll}
1 & x_{1} & x_{2}
\end{array}\right)\left(\begin{array}{l}
a_{0} \\
a_{1} \\
a_{2}
\end{array}\right) \\
=\mathbf{c a}
\end{aligned}
$$

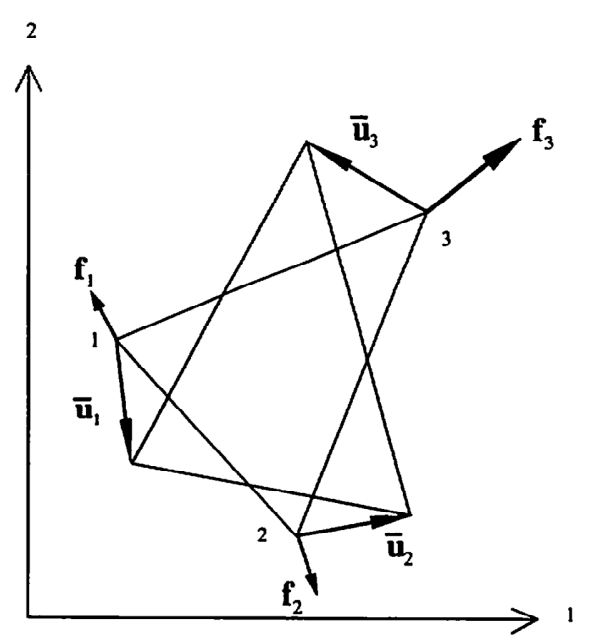

Figure A1. Force vector and virtual displacement vector work at each nodal point in a certain finite element (Hayashi, 2008).
Then, to obtain the practical form of (1), we assume the displacement within element as a function of coordinates. Since the simplest relation is linear, we take linear relation as follows.

$$
\left(\overline{\mathbf{u}}^{e}\right)^{T} \mathbf{f}^{e}=\int_{S}\left(\overline{\mathbf{e}}^{e}\right)^{T} \mathbf{s} d S
$$

Substituting the values of coordinate and displacement at nodes into this equation, we have

$$
u_{N}=\left(\begin{array}{lll}
1 & x_{N 1} & x_{N 2}
\end{array}\right) \mathbf{a}
$$

Writing in vector form

$$
\mathbf{u}^{\mathrm{e}}=\left(\begin{array}{l}
u_{1} \\
u_{2} \\
u_{3}
\end{array}\right)=\left[\begin{array}{lll}
1 & x_{11} & x_{12} \\
1 & x_{21} & x_{22} \\
1 & x_{31} & x_{32}
\end{array}\right] \mathbf{a}=C \mathbf{a}
$$

The coefficient vector $\mathbf{a}$ is derived from the equation,

$$
\begin{gathered}
\mathbf{a}=C^{-1} \mathbf{u}^{e} \\
C^{-1}=\frac{1}{\Delta}\left[\begin{array}{lll}
\Delta_{11} & \Delta_{21} & \Delta_{31} \\
\Delta_{12} & \Delta_{22} & \Delta_{32} \\
\Delta_{13} & \Delta_{23} & \Delta_{33}
\end{array}\right]
\end{gathered}
$$

and $\Delta \equiv \operatorname{det} C$ and $\Delta_{i j} \equiv$ cofactor of $C$.

Therefore, the inner displacement is represented in terms of nodal displacements

$$
\begin{aligned}
u= & \mathrm{c} C^{-1} \mathrm{u}^{e} \\
= & \frac{1}{\Delta}\left(\Delta_{11}+\Delta_{12} x_{1}+\Delta_{13} x_{2} \quad \Delta_{21}+\Delta_{22} x_{1}+\Delta_{23} x_{2}\right. \\
& \left.\Delta_{31}+\Delta_{32} x_{1}+\Delta_{32} x_{2}\right) \mathrm{u}^{e}
\end{aligned}
$$

Replacing as $\phi_{N}=\frac{1}{\Delta}\left(\Delta_{N 1}+\Delta_{N 2} x_{1}+\Delta_{N 3} x_{2}\right)$, we have $u=\phi_{N} u_{N}$.

Since we will consider 2D situation, displacement has 2 components as $\boldsymbol{u}_{1}$ and $\boldsymbol{u}_{2}$.

$$
\begin{aligned}
& u_{1}=\phi_{N} u_{N 1} \\
& u_{2}=\phi_{N} u_{N 2}
\end{aligned}
$$

Writing them in vector form,

$$
\mathbf{u}=\left(\begin{array}{l}
u_{1} \\
u_{2}
\end{array}\right)=\left[\begin{array}{cccccc}
\phi_{1} & \phi_{2} & \phi_{3} & 0 & 0 & 0 \\
0 & 0 & 0 & \phi_{1} & \phi_{2} & \phi_{3}
\end{array}\right]\left(\begin{array}{l}
\mathbf{u}_{1} \\
\mathbf{u}_{2}
\end{array}\right)
$$

Then, exchanging the order of nodal displacements,

$$
\begin{aligned}
u_{11} u_{21} u_{31} u_{12} u_{22} u_{32} \Rightarrow u_{11} u_{12} u_{21} u_{22} u_{31} u_{32} \\
\mathbf{u}=\left(\begin{array}{l}
u_{1} \\
u_{2}
\end{array}\right)=\left[\begin{array}{cccccc}
\phi_{1} & 0 & \phi_{2} & 0 & \phi_{3} & 0 \\
0 & \phi_{1} & 0 & \phi_{2} & 0 & \phi_{3}
\end{array}\right]\left(\begin{array}{l}
u_{11} \\
u_{12} \\
u_{21} \\
u_{22} \\
u_{31} \\
u_{32}
\end{array}\right) \\
=\Phi \mathbf{u}^{e}
\end{aligned}
$$


Then, we can represent strain by nodal displacements as

$$
\begin{aligned}
\mathbf{e} & =\left(\begin{array}{l}
e_{11} \\
e_{22} \\
2 e_{12}
\end{array}\right)=\left(\begin{array}{l}
u_{1,1} \\
u_{2,2} \\
u_{1,2}+u_{2,1}
\end{array}\right)=\left[\begin{array}{cccccc}
\phi_{1,1} & 0 & \phi_{2,1} & 0 & \phi_{3,1} & 0 \\
0 & \phi_{1,2} & 0 & \phi_{2,2} & 0 & \phi_{3,2} \\
\phi_{1,2} & \phi_{1,1} & \phi_{2,2} & \phi_{2,1} & \phi_{3,2} & \phi_{3,1}
\end{array}\right] \mathbf{u}^{e} \\
& =B \mathbf{u}^{e}
\end{aligned}
$$

Where

$$
B=\frac{1}{\Delta}\left[\begin{array}{cccccc}
\Delta_{12} & 0 & \Delta_{22} & 0 & \Delta_{32} & 0 \\
0 & \Delta_{13} & 0 & \Delta_{23} & 0 & \Delta_{33} \\
\Delta_{13} & \Delta_{12} & \Delta_{23} & \Delta_{22} & \Delta_{33} & \Delta_{32}
\end{array}\right]
$$

As for stress vector, according to the constitutive law of elasticity,

$$
\mathbf{s}=\left(\begin{array}{l}
\sigma_{11} \\
\sigma_{22} \\
\sigma_{12}
\end{array}\right)=D \mathbf{e}
$$

For example, in case of plane strain

$$
D=\frac{E(1-v)}{(1+v)(1-2 v)}\left[\begin{array}{ccc}
1 & \frac{v}{1-v} & 0 \\
\frac{v}{1-v} & 1 & 0 \\
0 & 0 & \frac{1-2 v}{2(1-v)}
\end{array}\right]
$$

Then, according to the principle of virtual work,

$$
\begin{aligned}
& =\left(\overline{\mathbf{e}}^{e}\right)^{T}\left[\int_{S} B^{T} D B d S\right] \mathbf{u}^{e} \\
& \mathbf{f}^{e}=K^{e} \mathbf{u}^{e}
\end{aligned}
$$

This is called the stiffness equation of element.

Superposing every stiffness equations of element, we obtain the stiffness equation of whole domain. $\mathbf{F}=\mathbf{K} \mathbf{u}$

$$
\left(\overline{\mathbf{u}}^{e}\right)^{T}\left(\mathbf{f}^{e}-\int_{S} \mathbf{f}_{b} d S\right)=\int_{S}(\overline{\mathbf{e}})^{T} \mathbf{s} d S
$$

If body force ( $\mathrm{fb}$ ) is considered, the principle of virtual work need be modified as

\section{Fault Analysis}

As shown in Figure A2, the Mohr-Coulomb criterion is written as a linear relationship between shear and normal stresses,

$$
\sigma^{*}=v\left(\sigma_{1}+\sigma_{2}\right)
$$

When we consider the analysis in plane strain condition, it is possible to calculate the value of third principal stress $\left(\sigma^{*}\right)$, where $v$ is the Poisson ratio (Timoshenko and Goodier, 1970). After comparing the values of $\sigma_{1}$, $\sigma_{2}$ and $\sigma^{*}$, we can recognize the newly defined $\sigma_{1}$, $\sigma_{2}$ and $\sigma_{3}$ as the maximum, intermediate and mini mum principal stresses respectively. We introduce how

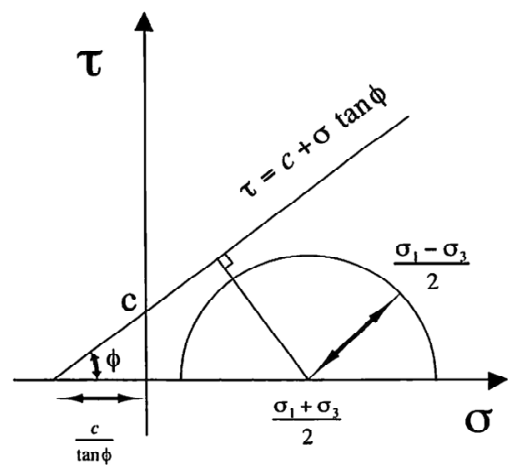

Figure A2. Failure envelope and Mohr's circle in $\sigma-\tau$ space. $c$ is cohesion and $\varphi$ is angle of internal friction (Hayashi, 2008).

mum principal stresses respectively. We introduce how the Mohr-Coulomb criterion is combined into the FE software package; though I already wrote the method of failure analysis in my serial papers (Table 1).

If body force $\left(\mathbf{f}_{b}\right)$ is considered, the principle of virtual work need be modified as

$$
\tau=c+\sigma \tan \phi
$$

where $c$ and $\phi$ are the cohesive strength and the angle of internal friction, respectively. Failure will observe when the Mohr's circle first touches the failure envelope (3). It will happen when the radius of the Mohr's circle, $\sigma_{1}+\sigma_{2} / 2$, is equal to the perpendicular distance from the center of the circle at $\sigma_{1}-\sigma_{2} / 2$ to the failure envelope,

$$
\left(\frac{\sigma_{1}-\sigma_{3}}{2}\right)_{\text {failure }}=c \cos \phi+\left(\frac{\sigma_{1}+\sigma_{3}}{2}\right) \sin \phi
$$

According to Melosh and Williams (1989), the proximity to failure $\left(P_{f}\right)$ is the ratio between the calculated stress and the failure stress, which is given by

$$
P_{f}=\left[\frac{\left(\frac{\sigma_{1}-\sigma_{3}}{2}\right)}{\left(\frac{\sigma_{1}-\sigma_{3}}{2}\right)_{\text {failure }}}\right]
$$

When the ratio reaches one $\left(P_{f}=1\right)$, failure occurs, but when $P_{f}<1$ stress is within the failure envelope, rock does not fail. The proximity to failure $P_{f}$ reveals which parts of the model are close to failure or already failed by generating faults.

The type of faulting has been determined by the Anderson's theory (1951). According to his theory three classes of faults (normal, strike slip and thrust) result from the three principal classes of inequality that may exist between the principal stresses. I realized the judgment in the program failure.state.func in FE package. 